\title{
MacArthur Competence Assessment Tool for Treatment in Alzheimer disease: cross-cultural adaptation
}

\author{
MacArthur Competence Assessment Tool for Treatment na doença de Alzheimer: \\ adaptação transcultural
}

Raquel Luiza Santos ${ }^{1}$, Maria Fernanda Barroso de Sousa ${ }^{1}$, José Pedro Simões Neto², Elodie Bertrand ${ }^{3}$, Daniel C. Mograbi, ${ }^{3,4}$, Jesus Landeira-Fernandez ${ }^{3}$, Jerson Laks' ${ }^{1}$, Marcia Cristina Nascimento Dourado ${ }^{1}$

\begin{abstract}
Objective: We adapted the MacArthur Competence Assessment Tool for Treatment (MacCAT-T) to Brazilian Portuguese, pilot testing it on mild and moderate patients with Alzheimer's disease (AD). Methods: The cross-cultural process required six steps. Sixty-six patients with AD were assessed for competence to consent to treatment, global cognition, working memory, awareness of disease, functionality, depressive symptoms and dementia severity. Results: The items had semantic, idiomatic, conceptual and experiential equivalence. We found no difference between mild and moderate patients with AD on the MacCAT-T domains. The linear regressions showed that reasoning $(p=0.000)$ and functional status ( $p=0.003)$ were related to understanding. Understanding $(p=0.000)$ was related to appreciation and reasoning. Awareness of disease $(p=0.001)$ was related to expressing a choice. Conclusions: The MacCAT-T adaptation was well-understood and the constructs of the original version were maintained. The results of the pilot study demonstrated an available Brazilian tool focused on decision-making capacity in AD.
\end{abstract}

Keywords: decision making; mental competency; geriatric assessment; Alzheimer disease; translating.

\section{RESUMO}

Objetivo: Adaptamos o MacArthur Competence Assessment Tool for Treatment (MacCAT-T) para o português brasileiro, realizando estudo piloto em amostra de pessoas com doença de Alzheimer (DA) leve e moderada. Métodos: O processo transcultural apresentou seis passos. Posteriormente, avaliamos competência para consentimento do tratamento, cognição global, memória de trabalho, consciência da doença, funcionalidade, sintomas depressivos e gravidade da doença de 66 pessoas com DA. Resultados: Os itens apresentaram equivalência semântica, idiomática, conceitual e experiencial. Não encontramos diferenças entre pessoas com DA leve e moderada nos domínios do MacCAT-T. Regressões lineares demonstraram que raciocínio $(p=0.000)$ e funcionalidade $(p=0.003)$ estavam relacionados à compreensão. Compreensão ( $p=0.000$ ) estava relacionada ao julgamento e raciocínio. Consciência da doença $(p=0.001)$ estava relacionada à expressão da escolha. Conclusões: A adaptação da MacCAT-T foi bem compreendida e os constructos da versão original mantidos. Resultados do estudo piloto apontaram disponibilidade de ferramenta brasileira sobre tomada de decisões na DA.

Palavras-chave: tomada de decisões; competência mental; avaliação geriátrica; doença de Alzheimer; tradução.

Competence to consent to treatment is the ability to accept a treatment, refuse it or select among alternatives ${ }^{1}$. It relies on four abilities: understanding the information about diagnosis and treatment, appreciating the situation and its consequences, reasoning about treatment options regarding consequences for everyday life, and expressing a choice ${ }^{2}$. Any degree of interference on each of these four abilities may lead to impaired competence to consent to treatment ${ }^{3}$.

Previous research among patients with $\mathrm{AD}$ has shown that decreased cognitive function and the presence of

\footnotetext{
${ }^{1}$ Universidade Federal do Rio de Janeiro, Instituto de Psiquiatria, Centro para Doença de Alzheimer e Outros Transtornos Mentais na Velhice, Rio de Janeiro RJ, Brasil; ${ }^{2}$ Universidade Federal de Santa Catarina, Departamento de Sociologia Política, Florianópolis SC, Brasil;

${ }^{3}$ Pontifícia Universidade Católica do Rio de Janeiro, Departamento de Psicologia, Rio de Janeiro RJ, Brasil;

${ }^{4}$ King's College London, Institute of Psychiatry, Department of Psychology, London, UK.

Correspondence: Raquel Luiza Santos; Rua Constança Barbosa, 140/504; 20735-090 Rio de Janeiro RJ, Brasil; E-mail: raquelluizasantos@yahoo.com.br Conflict of interest: There is no conflict of interest to declare.

Support: Fundação de Amparo à Pesquisa do Estado do Rio de Janeiro (Edital FAPERJ n. 06/2013, Programa Pró-Idoso - "Apoio ao Estudo de Temas Relacionados à Saúde e Cidadania de pessoas Idosas - 2013”, FAPERJ, E-26/110.070/2013), and Coordenação de Aperfeiçoamento de Pessoal de Nivel Superior (CAPES)

Received 14 July 2016; Accepted 13 September 2016.
} 
neuropsychiatric symptoms may impair competence to consent to treatment even in the very mild stages of the disease ${ }^{4,5}$. Although such individuals may be able to express their choice, deficits in semantic knowledge and learning/recall of complex verbal information may impair the process of understanding ${ }^{1}$. Additionally, executive dysfunction may reduce the ability to organize and process conceptual information regarding personal values ${ }^{1}$. Some studies suggest that competence to consent to treatment might be intact in the early clinical stages of Alzheimer's disease $(\mathrm{AD})^{6,7}$, especially when the person has more preserved cognition ${ }^{8}$.

The MacArthur Competence Assessment Tool for Treatment (MacCAT-T) ${ }^{9}$ is a tool focused on clinical assessment ${ }^{2,9,10}$. It has successfully been applied to people with dementia, mild cognitive impairment, schizophrenia and major depressive disorder ${ }^{11,12}$. This instrument offers a flexible yet structured method with which health professionals can assess, rate and report the relevant abilities of competence to consent to treatment ${ }^{9}$.

Despite its importance, competence to consent to treatment in $\mathrm{AD}$ has been overlooked in Brazil. There are no Brazilian Portuguese instruments for the assessment of this construct in $\mathrm{AD}$. To reduce this knowledge gap, we sought to apply the cross-cultural adaptation process of the MacCAT-T to Brazilian Portuguese. We also aimed to perform a pilot study among a sample of outpatients with $\mathrm{AD}$ who attended a psychogeriatric unit in Rio de Janeiro, Brazil.

\section{METHODS}

The MacCAT-T is a semi-structured interview that incorporates specific information from each person's chart to assess the decision-making abilities for judgments about competence to consent to treatment ${ }^{2,9,10}$. The health professional initially fills in the MacCAT-T record form with information about the individual's symptoms, diagnosis and treatment needs ${ }^{9}$. The interview starts with a disclosure of the nature of the disorder and treatment, its benefits and risks, and alternative treatments ${ }^{9}$. There are questions to assess understanding, appreciation and reasoning and, finally, the interviewee is supposed to offer a clear expression of a treatment choice and to explain how this choice was made? The understanding section is divided into understanding the disorder, understanding the treatment and understanding the benefits and risks, and it assesses the capacity to paraphrase what has been disclosed ${ }^{9}$. If there is any sign of poor understanding, the interviewer must redisclose the information and reassess the patient ${ }^{9}$. The appreciation section assesses whether the individual acknowledges that the disclosed information applies to him or her (appreciation of the disorder subscale) and whether he or she recognizes the possible treatment benefits (appreciation of the treatment) ${ }^{9}$. Reasoning explores whether the person mentions any consequence of the treatment alternatives (consequential thinking), any comparison among alternatives (comparative thinking) and any consequences that were not mentioned in the disclosure (generating consequences) ${ }^{9}$. Finally, the expression of a choice occurs when the person establishes a preference for a treatment option ${ }^{9}$.

The complete process requires approximately 15-20 minutes to administer and 2-3 minutes to score ${ }^{2,9,10}$. Ratings for each item are 2 (adequate), 1 (partially adequate) and 0 (inadequate) ${ }^{9}$. There is a quantitative score for each of the four abilities: 0-6 for understanding, 0-4 for appreciation, 0-8 for reasoning and 0-2 for expressing a choice ${ }^{2,9,10}$. The method does not offer a total score or a cutoff for competence, but the evaluators must integrate the results with other relevant clinical information to reach a judgment ${ }^{2,9,10}$. The feasibility, reliability and validity of this instrument have been tested, with excellent inter-rater reliability $(\mathrm{k}>0.8)^{9}$. Intraclass correlations calculated among three raters were.99 for understanding, 0.87 for appreciation,.91 for reasoning and.97 for expressing a choice $e^{9,11}$.

\section{Cross-cultural adaptation}

The cross-cultural adaptation process was based on the standardized procedures proposed by Beaton et al. ${ }^{13}$. Initially, we contacted the original authors of MacCAT-T and obtained their formal authorization to conduct the adaptation of the instrument to Brazilian Portuguese. The following consecutive steps were carried out: initial translation, translation synthesis, back translation, committee of judges, pretest of the final version and submission to the author of the original instrument ${ }^{13}$.

\section{Initial translation}

Two independent translators $(\mathrm{T} 1, \mathrm{~T} 2)$ performed the initial translation of the original English version of the instrument into Brazilian Portuguese. The translator T1 was an experienced psychologist in the area, capable of identifying the constructs of the instrument ${ }^{13}$. To minimize the influence of academic jargon, the translator T2 did not have any knowledge of the MacCAT-T content and had no medical or clinical background ${ }^{13}$. In this step, we aimed to maintain operational equivalence with the items of the MacCAT-T, the formatting of all questions and instructions, and the application procedures of the instrument ${ }^{13}$.

\section{Translation synthesis}

The two translators and a recording observer, who did not participate in the first step, analyzed the two initial translations. Based on the results of this analysis, a synthetic version was produced ${ }^{13}$.

\section{Back translation}

We handed the synthetic version to a bilingual psychologist with previous knowledge about competence to consent to treatment, but blind to the original instrument ${ }^{13}$. The aim 
of this step was to verify any type of inconsistency or conceptual error of the translations ${ }^{13}$. We sent this version to the authors of the original scale to evaluate and approve the adjustments that had been made to translate the instrument into Portuguese ${ }^{13}$.

\section{Committee of judges}

The fourth stage involved the organization of a committee of judges to evaluate the equivalence between the original version and the Brazilian version of the instrument ${ }^{13}$. The judges were eight mental health professionals: two psychiatrists and six psychologists. The committee evaluated: (1) the content in relation to the literal translation of the words (semantic equivalence), (2) the presence of colloquialisms and linguistic expressions (idiomatic equivalence), (3) the concept of the phenomenon assessed (conceptual equivalence), and (4) the culture experienced regarding the target population's daily life (experiential equivalence $)^{13}$. After the suggestions of the committee, a new synthetic version in Portuguese was proposed ${ }^{13}$.

\section{Pretest of the final version}

As a pretest, the new synthetic version was applied to 20 participants with possible or probable $\mathrm{AD}$ according to the Diagnostic and Statistical Manual of Mental Disorders, fourth edition ${ }^{14}$, to verify its comprehension by our target population ${ }^{13}$. No difficulties were observed in the administration and comprehension of the instrument.

\section{Submission to the author of the original instrument}

The back translation of the final Brazilian version was submitted to the author of the original instrument to ensure that the adapted version was compatible with the original one ${ }^{13}$. After this step, we performed a pilot study of the final version.

\section{Pilot study of the final version}

\section{Participants}

The study included 66 participants diagnosed with possible or probable $\mathrm{AD}$ according to the Diagnostic and Statistical Manual of Mental Disorders, fourth edition ${ }^{14}$. The participants attended an outpatient clinic and were consecutively selected, according to the psychiatrists' referrals, from January 2014 to August 2015. The clinical diagnosis of AD was made by a psychiatrist, based on clinical interviews with the patients with $\mathrm{AD}$ and his or her caregiver, cognitive screening tests, laboratory tests and imaging studies. Inclusion criteria, according to the Clinical Dementia Rating (CDR), were: mild $(\mathrm{CDR}=1 ; \mathrm{N}=45)$ and moderate $(\mathrm{CDR}=2 ; \mathrm{N}=21)$ dementia $^{15,16}$ and Mini-Mental State Examination (MMSE) ${ }^{17,18}$ scores of 11-26. We excluded people with head trauma, aphasia, history of alcoholism, psychotic symptoms, epilepsy and uncontrolled medical problems such as hypertension, depression and diabetes.

\section{Instruments}

1) Competence to consent to treatment

The MacCAT-T ${ }^{9}$ (adapted to Brazilian Portuguese) was used to assess competence to consent to treatment.

2) Cognition

We used the MMSE ${ }^{17,18}$. The total score ranges from 0 to 30. Lower scores indicate impaired cognition ${ }^{17,18}$.

We also applied the Alzheimer Disease Assessment Scale - Cognitive Subscale ${ }^{19}$, which assesses the intensity of cognitive changes. The cognitive subscale includes 11 items, with a maximum score of 70 . Higher scores indicate a poor performance $^{19}$.

We assessed working memory with the Wechsler Digit Span Test ${ }^{20,21}$. The total scores vary from 0 to 30 and higher scores indicate a better performance.

3) Awareness of disease

We applied the Assessment Scale of Psychosocial Impact of the Diagnosis of Dementia ${ }^{22}$, a 30-question scale based on the scoring of discrepant responses between the reports of people with dementia and their caregivers. The ratings of awareness are preserved (0-4), mildly impaired (5-11), moderately impaired (12-17) and absent (over 18), with one point being scored for each discrepant response ${ }^{22}$.

4) Functionality

We applied the Pfeffer Functional Activities Questionnaire ${ }^{23}$. The ratings for each item range from normal (0) to dependent (3), with a total of 30 points. Higher scores indicate worse functional status ${ }^{23,24}$.

5) Neuropsychiatric symptoms

We applied the Neuropsychiatric Inventory ${ }^{25,26}$. Each item is rated in relation to their frequency [one (absent) to four (frequent)] and intensity [one (mild) to three (severe)]. The total score ranges from zero to 144 points $^{25,26}$ and higher scores indicate more frequent and severe neuropsychiatric symptoms.

6) Depressive symptoms

We applied Cornell Scale for Depression in Dementia ${ }^{27,28}$. The scores vary from 0 to 38 and scores above 13 indicate the presence of depression ${ }^{27,28}$.

7) Dementia severity

We applied the Clinical Dementia Rating ${ }^{15,16}$. The stages of dementia range from 0 (no dementia) to 3 (severe dementia). We used the full protocol ${ }^{15,16}$.

\section{Ethical issues}

The study was approved by the Ethics in Research Committee of the Institute of Psychiatry (IPUB) of the Universidade Federal do Rio de Janeiro (UFRJ). All patients with $\mathrm{AD}$ and their caregivers signed consent terms.

\section{Statistical analysis}

All variables were inspected for normality before analysis. The parametric variables were described by their mean and standard deviations (SD). To verify the relationship between 
the domains of the MacCAT-T (understanding, appreciation, reasoning and expressing a choice) and age, schooling, duration of the disease, MMSE, Alzheimer Disease Assessment Scale - Cognitive Subscale, Wechsler Digit Span Test, Assessment Scale of Psychosocial Impact of the Diagnosis of Dementia, Neuropsychiatric Inventory, Cornell Scale for Depression in Dementia and Pfeffer Functional Activities Questionnaire, we used Pearson's correlations. To control for the family wise error rate, only results with $p \leq 0.001$ were considered significant. The independent samples t-tests also explored the relationship between the domains of the MacCAT-T (understanding, appreciation, reasoning and expressing a choice) and the Clinical Dementia Rating.

Next, we built four models of linear regression, each of them containing, as a dependent variable, one of the domains of the MacCAT-T (understanding, appreciation, reasoning and expressing a choice). We only included independent variables that were significantly associated with the dependent ones. The final models had better adjustment among the variables, as well as better explanatory power.

The level of statistical significance was set at.05. All data processing and analysis were performed using SPSS v22.0 for Windows.

\section{RESULTS}

\section{Cross-cultural adaptation}

During the development of the translation synthesis, we aimed to reach a consensus regarding the best translation options. We prioritized the use of colloquial language. The back translation had good equivalence regarding the reference framework and general meaning in comparison with the original instrument. The committee of judges analyzed the initial translations, the translation synthesis and the back translation. All items had semantic, idiomatic, conceptual and experiential equivalence. However, operational adjustments were proposed.

First of all, on the item "Understanding - Disorder" ("Compreendendo a doença") the committee of judges agreed that we should ask the participants to explain in their own words what they understood by: "You are in treatment here because of memory problems". We considered this alteration to ensure that the MacCAT-T was applicable to cases of partial awareness or unawareness of the disease. Instead of the term "alternative treatments", we chose to apply the term "complementary treatments" ("tratamentos complementares"). In this case, the health professional was supposed to inform the patients with $\mathrm{AD}$ that, in the psychogeriatric unit, the medical treatment could be complemented by other interventions, such as day center, individual/group psychotherapy, music therapy and physiotherapy. Patients with $\mathrm{AD}$ were also allowed to mention other interventions that they might consider as complementary to the pharmacological treatment (such as going to the gym, practising foreign language/arts and crafts, participating in spiritual or religious interventions, etc.).

Finally, on the item "first choice and reasoning"("primeira escolha e raciocinio"), we included three options to be explained to the patients with $\mathrm{AD}$ : no treatment ("nenhum tratamento"), only pharmacological treatment ("apenas tratamento medicamentoso") and pharmacological treatment associated with complementary treatment ("tratamento medicamentoso combinado com tratamentos complementares"). The committee of judges considered that the inclusion of these three options would reduce the scope of alternatives presented to the patients with $\mathrm{AD}$.

The summary of items in the original instrument and their cross-cultural adaptation are shown in Table 1.

\section{Pilot study of the final version}

\section{Sociodemographic and clinical characteristics}

Most participants in our sample $(n=66)$ were women $(56.1 \% ; \mathrm{n}=37)$. The sample showed a mean age of 78 years old $(\mathrm{SD}=6.4)$ and a mean of 7.3 years of education $(\mathrm{SD}=3.7)$. Most participants had mild dementia (CDR 1; 68.2\%; $\mathrm{n}=45$ ). The sociodemographic and clinical characteristics of the sample are presented in Table 2 .

\section{Factors related to the domains of the MacCAT-T}

\section{Univariate analysis}

Upon analyzing the domains of the MacCAT-T, we found that understanding was correlated with appreciation $(\mathrm{r}=0.47 ; \mathrm{p}=0.000)$, reasoning $(\mathrm{r}=0.48 ; \mathrm{p}=0.000)$, working memory $(r=0.33 ; p=0.007)$ and functional status $(r=-0.32 ; p=0.008)$. Moreover, we observed that appreciation was correlated with understanding $(r=0.47$; $\mathrm{p}=0.000)$, reasoning $(\mathrm{r}=0.41 ; \mathrm{p}=0.001)$ and awareness of disease $(r=-0.32 ; p=0.008)$. Reasoning was correlated with understanding $(r=0.48 ; \mathrm{p}=0.000)$ and appreciation ( $r=0.41 ; p=0.001)$. Expressing a choice was correlated with awareness of disease $(r=-0.39$; $p=0.001)$. We found no difference between patients with mild and moderate $\mathrm{AD}$ in the four domains of the MacCAT-T. The significant and non-significant correlations between the domains of the MacCAT-T and the sociodemographic and clinical variables are presented in Table 3.

\section{Multivariate analysis}

\section{Factors related to understanding}

The regression indicated that reasoning $(\mathrm{p}<0.001)$ and functionality $(\mathrm{p}<0.01)$ were significantly related to understanding. The final model with the factors associated with understanding explained $33.2 \%$ of the observed variance $(\mathrm{p}<0.001)$. The adjusted R-squared values and the standardized regression weights are presented in Table 4. 


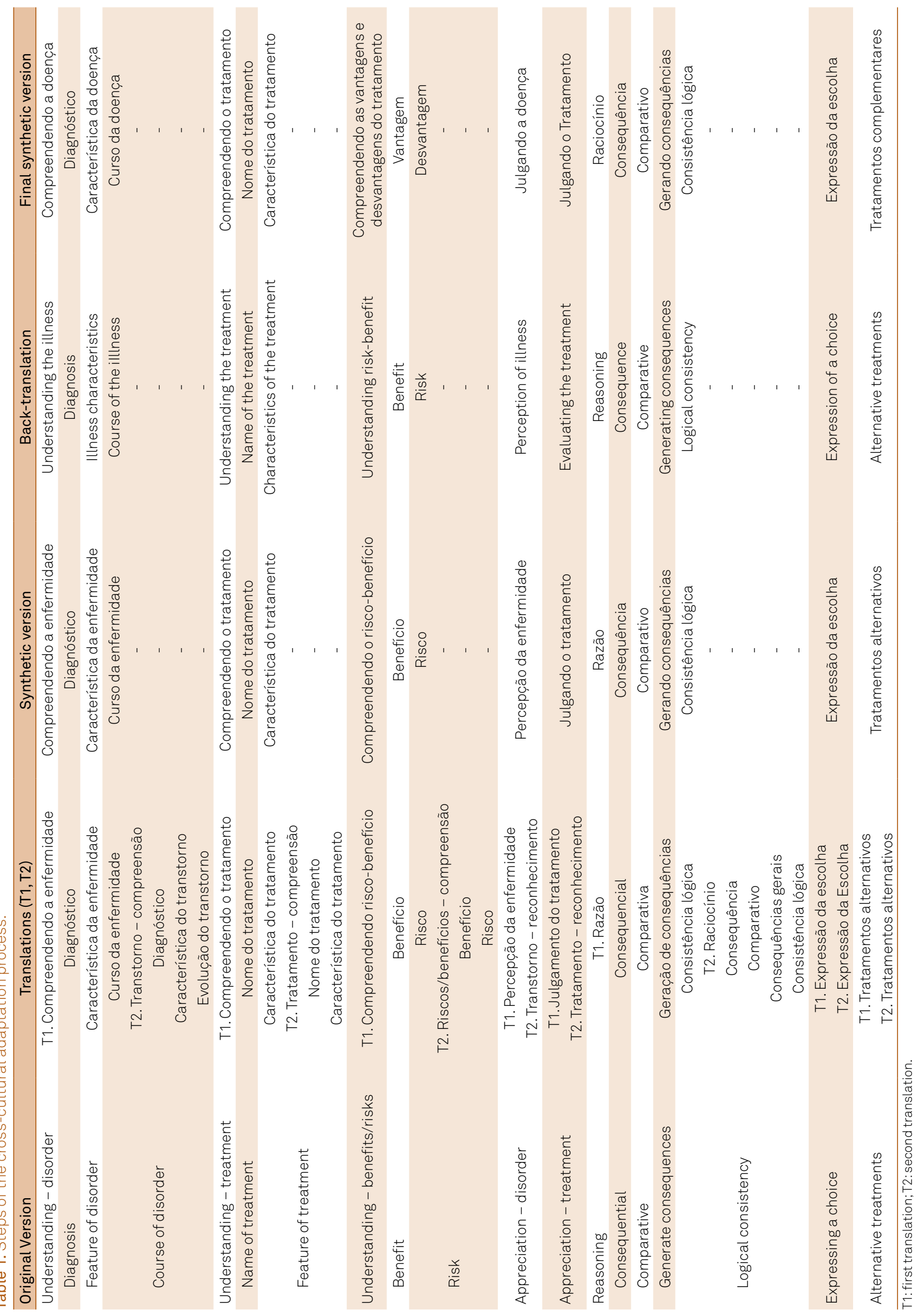




\section{Factors related to appreciation}

The regression indicated that understanding $(\mathrm{p}<0.001)$ was significantly related to appreciation. The final model with the factors associated with appreciation explained $22.2 \%$ of the observed variance $(p<0.001)$. The adjusted

Table 2. Sociodemographic and clinical characteristics of the sample.

\begin{tabular}{|c|c|}
\hline Variable & People with AD $(n=66)$ \\
\hline Female, n (\%) & $37(56.1)$ \\
\hline Age, mean (SD) & $78.0 \pm 6.4$ \\
\hline Schooling, mean (SD) & $7.3 \pm 3.7$ \\
\hline Duration of disease, mean (SD) & $5.3 \pm 3.5$ \\
\hline CDR 1, n (\%) & $45(68.2)$ \\
\hline Married & $38(57.6)$ \\
\hline Widow & $24(36.4)$ \\
\hline Divorced & $3(4.5)$ \\
\hline Single & $1(1.5)$ \\
\hline MMSE, mean (SD) & $19.2 \pm 3.9$ \\
\hline ADAS-Cog, mean (SD) & $24.3 \pm 8.5$ \\
\hline Digit span test, mean (SD) & $10.8 \pm 3.7$ \\
\hline ASPIDD, mean (SD) & $9.7 \pm 5.3$ \\
\hline NPI, mean (SD) & $14.9 \pm 12.3$ \\
\hline CSDD, mean (SD) & $8.0 \pm 5.3$ \\
\hline PFAQ, mean (SD) & $17.4 \pm 8.0$ \\
\hline \multicolumn{2}{|l|}{ MacCAT-T (SD) } \\
\hline Understanding, mean & $4.2 \pm 1.0$ \\
\hline Appreciation, mean & $3.3 \pm 1.0$ \\
\hline Reasoning, mean & $3.2 \pm 1.5$ \\
\hline Expressing a choice, mean & $1.8 \pm 0.5$ \\
\hline \multicolumn{2}{|c|}{$\begin{array}{l}\text { AD: Alzheimer's disease; SD: standard deviation; CDR: clinical dementia } \\
\text { rating; MMSE: mini-mental state examination; ADAS-Cog: Alzheimer disease } \\
\text { assessment scale - cognitive subscale; ASPIDD: assessment scale of } \\
\text { psychosocial impact of the diagnosis of dementia; NPI: neuropsychiatric } \\
\text { inventory; CSDD: Cornell scale for depression in dementia; PFAQ: Pfeffer } \\
\text { functional activities questionnaire; MacCAT-T: MacArthur competence } \\
\text { assessment tool for treatment. }\end{array}$} \\
\hline
\end{tabular}

R-squared values and the standardized regression weights are presented in Table 4.

\section{Factors related to reasoning}

The regression indicated that understanding $(\mathrm{p}<0.001)$ was significantly related to reasoning. The final model with the factors associated with reasoning explained $23.4 \%$ of the observed variance $(\mathrm{p}<0.001)$. The adjusted R-squared values and the standardized regression weights are presented in Table 4.

\section{Factors related to expressing a choice}

The regression indicated that awareness of the disease $(p<0.001)$ was significantly related to expressing a choice. The final model with the factors associated with expressing a choice explained $15.3 \%$ of the observed variance $(\mathrm{p}<0.001)$.

\section{DISCUSSION}

The primary aim of this study was to culturally adapt the MacCAT-T to the Brazilian population with AD. While the original concept of the instrument was preserved, we rigorously considered the language differences, cultural specificities and lifestyle of the target population ${ }^{13}$. Therefore, the cross-cultural adaptation of the MacCAT-T to Brazilian Portuguese had semantic, idiomatic, conceptual and experiential equivalence to the original characteristics of the instrument.

We observed that understanding, appreciation and reasoning were related to each other. This result is in line with the suggestion that any degree of interference with any single ability may result in impaired competence to consent to treatment ${ }^{3}$. Moreover, our results also showed that expressing a choice

Table 3. Correlations between the four domains of the MacCAT-T (MacArthur Competence Assessment Tool for Treatment) and study variables.

\begin{tabular}{|c|c|c|c|c|c|c|c|c|}
\hline \multirow{2}{*}{ Variable } & \multicolumn{2}{|c|}{ Understanding } & \multicolumn{2}{|c|}{ Appreciation } & \multicolumn{2}{|c|}{ Reasoning } & \multicolumn{2}{|c|}{ Expressing a choice } \\
\hline & $\mathrm{R}$ & $\mathrm{P}$ & $\mathrm{R}$ & $\mathrm{P}$ & $\mathrm{R}$ & $\mathrm{P}$ & $\mathrm{R}$ & $\mathrm{P}$ \\
\hline Understanding & - & - & 0.471 & $0.000^{*}$ & 0.484 & $0.000 *$ & 0.106 & 0.397 \\
\hline Appreciation & 0.471 & $0.000 *$ & - & - & 0.411 & $0.001 *$ & 0.272 & 0.027 \\
\hline Reasoning & 0.484 & $0.000 *$ & .0411 & $0.001 *$ & - & - & 0.166 & 0.183 \\
\hline Expressing a choice & 0.106 & 0.397 & 0.272 & 0.027 & 0.166 & 0.183 & - & - \\
\hline Age & -0.140 & 0.262 & -0.309 & 0.012 & -0.142 & 0.256 & 0.061 & 0.627 \\
\hline Schooling & 0.054 & 0.667 & 0.177 & 0.156 & 0.213 & 0.085 & 0.142 & 0.255 \\
\hline Duration of disease & -0.078 & 0.538 & -0.089 & 0.483 & -0.051 & 0.684 & 0.027 & 0.832 \\
\hline MMSE & 0.240 & 0.052 & 0.059 & 0.636 & 0.188 & 0.130 & -0.013 & 0.919 \\
\hline ADAS-Cog & -0.222 & 0.074 & -0.008 & 0.949 & -0.226 & 0.068 & 0.015 & 0.907 \\
\hline Digit span & 0.328 & $0.007^{\star}$ & 0.076 & 0.547 & 0.252 & 0.041 & -0.111 & 0.374 \\
\hline ASPIDD & -0.310 & 0.011 & -0.323 & $0.008^{*}$ & -0.156 & 0.211 & -0.391 & $0.001 *$ \\
\hline NPI & -0.125 & 0.317 & -0.87 & 0.486 & -0.89 & 0.477 & -0.275 & 0.025 \\
\hline CSDD & 0.045 & 0.719 & 0.026 & 0.836 & 0.080 & 0.521 & -0.074 & 0.553 \\
\hline PFAQ & -0.324 & $0.008^{*}$ & -0.181 & 0.146 & -0.024 & 0.847 & -0.181 & 0.145 \\
\hline
\end{tabular}

R:Correlation coefficient; P:Significance. MMSE: mini-mental state examination;ADAS-Cog:Alzheimer disease assessment scale - cognitive subscale;ASPIDD: assessment scale of psychosocial impact of the diagnosis of dementia; NPI: neuropsychiatric inventory; CSDD: Cornell scale for depression in dementia; PFAQ: Pfeffer functional activities questionnaire. ${ }^{*} p<0.01$; 
Table 4. Regression models of factors related to the four domains of the MacCAT-T (MacArthur Competence Assessment Tool for Treatment).

\begin{tabular}{|c|c|c|c|c|c|}
\hline Variable & $\mathrm{B}$ & $\beta$ & $\mathrm{R}^{2}$ & Adj. $\mathrm{R}^{2}$ & Significance \\
\hline \multicolumn{6}{|l|}{ Understanding } \\
\hline Reasoning & $0.318(p=0.000 * *)$ & 0.477 & 0.332 & 0.311 & $0.000 * \star$ \\
\hline PFAQ & $-0.039(p=0.003 *)$ & -0.313 & 0.332 & 0.311 & $0.000 * *$ \\
\hline \multicolumn{6}{|l|}{ Appreciation } \\
\hline Understanding & $0.485(p=0.000 * *)$ & 0.471 & 0.222 & 0.21 & $0.000 * *$ \\
\hline \multicolumn{6}{|l|}{ Reasoning } \\
\hline Understanding & $0.725(p=0.000 * *)$ & 0.484 & 0.234 & 0.222 & $0.000 * *$ \\
\hline \multicolumn{6}{|l|}{ Expressing a Choice } \\
\hline ASPIDD & $-0.41(p=0.001 *)$ & -0.391 & 0.153 & 0.139 & $0.000 * *$ \\
\hline
\end{tabular}

was not related to the other abilities; it was only related to the awareness of the disease. In practice, most mild to moderate patients with $\mathrm{AD}$ will be able to express a treatment choice, even if their ability to understand, appreciate or reason is inadequate to support the choice ${ }^{29}$, but patients with $\mathrm{AD}$ who had awareness of their overall cognitive function and diagnosis were more likely to be judged competent by physicians ${ }^{5}$.

Moreover, the factors related to understanding were reasoning and functional status. Among the four abilities, understanding is the most stringent consent standard, as it requires comprehension of factual knowledge and understanding of the treatment situation and choices ${ }^{1,4,629}$. In previous studies, it has been observed that competence to consent to treatment was especially impaired in patients with $\mathrm{AD}^{5}$ when cognitive functioning had significantly low scores ${ }^{29}$. The functional status is probably related to understanding because people with lower functional status may be less stimulated and this may hinder comprehension.

Awareness of disease was related to expressing a choice. One previous study showed that impairments in the abilities to understand, appreciate and reason are clinically significant among unaware patients with moderate $\mathrm{AD}^{8}$. This result supports that awareness of the deficit is an essential determinant of a person's decision-making abilities.

However, this study had one limitation. The sample selection did not allow a distinction between the results of mild and moderate patients with AD. Further studies are needed to understand competence to consent to treatment in patients with different levels of severity of $\mathrm{AD}$, since previous studies suggest that competence to consent to treatment might be intact in the early clinical stages of $\mathrm{AD}^{7,10}$.

The study of autonomy and capacity involves consenting to treatment and diagnostic procedures, signing informed consent for participation in research, driving safely, making sound financial decisions, designating a surrogate decision-maker in cases of incapacity, and creating a will ${ }^{30}$. Preventing patients with $\mathrm{AD}$ from participating in these decisions reduces their autonomy ${ }^{7}$. Thus, it raises ethical issues related to the balance between respecting people's autonomy and protecting them from the consequences of a risky decision ${ }^{3}$.

\section{References}

1. Marson DC. Loss of competency in Alzheimer's disease: conceptual and psychometric approaches. Int J Law Psychiatry. 2001;24(2-3):267-83. doi:10.1016/S0160-2527(01)00064-4

2. Appelbaum PS. Assessment of patients' competence to consent to treatment. N Engl J Med. 2007;357:1834-40. doi:10.1056/NEJMcp074045

3. Appelbaum PS. Consent in impaired populations. Curr Neurol Neurosci Rep. 2010;10(5):367-73. doi:10.1007/s11910-010-0123-5

4. Moye J, Karel MJ, Azar AR, Gurrera RJ. Capacity to consent to treatment: empirical comparison of three instruments in older adults with and without dementia. The Gerontologist. 2004;44(2):166-75. doi:10.1093/geront/44.2.166

5. Karlawish JH, Casarett DJ, James BD, Xie SX, Kim SY. The ability of persons with Alzheimer disease (AD) to make a decision about taking an AD treatment. Neurology. 2005;64(9):1514-9. doi:10.1212/01.WNL.0000160000.01742.9D

6. Okonkwo OC, Griffith HR, Belue K, Lanza S, Zamrini EY, Harrell LE et al. Medical decision-making capacity in patients with mild cognitive impairment. Neurology. 2007;69(15):1528-35. doi:10.1212/01.wnl.0000277639.90611.d9

7. Hamann J, Bronner K, Margull J, Mendel R, Diehl-Schmid J, Bühner $M$ et al. Patient participation in medical and social decisions in Alzheimer's disease. J Am Geriatr Soc. 2011;59(11):2045-52. doi:10.1111/j.1532-5415.2011.03661.x

8. Lui VWC, Lam LC, Chau RC, Fung AW, Wong BM, Leung GT et al. Capacity to make decisions on medication management in Chinese older persons with mild cognitive impairment and mild Alzheimer's disease. Int Psychogeriatr. 2012;24(7):1103-11. doi:10.1017/S1041610212000129

9. Grisso T, Appelbaum PS, Hill-Fotouhi C. The MacCAT-T: a clinical tool to assess patients' capacities to make treatment decisions. Psychiatr Serv.1997;48(11):1415-9. doi:10.1176/ps.48.11.1415

10. Karel MJ, Gurrera RJ, Hicken B, Moye, J. Reasoning in the capacity to make medical decisions: the consideration of values. $J$ Clin Ethics. 2010;21(1):58-71. 
11. Sturman ED. The capacity to consent to treatment and research: a review of standardized assessment tools. Clin Psychol Rev. 2005;25(7):954-74. doi:10.1016/j.cpr.2005.04.010

12. Lamont S, Jeon Y, Chiarella M. Assessing patient capacity to consent to treatment: an integrative review of instruments and tools. J Clin Nurs. 2013;22(17-18):2387-403. doi:10.1111/jocn.12215

13. Beaton DE, Bombardier C, Guillemin F, Ferraz MB. Guidelines for the process of cross-cultural adaptation of self-report measures. Spine. 2000;25(24):3186-91. doi:10.1097/00007632-200012150-00014

14. American Psychiatric Association. Diagnostic and statistic manual of mental disorders. 4th ed. Washington, DC: American Psychiatric Association; 2000.

15. Morris J. The Clinical Dementia Rating (CDR):current version and scoring rules. Neurology. 1993;43(11):2412-4. doi:10.1212/WNL.43.11.2412-a

16. Maia ALG, Godinho C, Ferreira ED, Almeida V, Schuh A, Kaye J et al. [Application of the Brazilian version of the CDR scale in samples of dementia patients]. Arq Neuropsiquiatr. 2006;64(2B):485-9. Portuguese. doi:10.1590/S0004-282X2006000300025

17. Folstein MF, Folstein SE, McHugh PR. "Mini-mental state": a practical method for grading the cognitive state of patients for the clinician. J Psychiatr Res. 1975;12(3):189-98. doi:10.1016/0022-3956(75)90026-6

18. Bertolucci PH, Brucki SM, Campacci SR, Juliano Y. [The mini-mental state examination in a general population: impact of educational status]. Arq Neuropsiquiatr. 1994;52(1):1-7. doi:10.1590/S0004-282X1994000100001

19. Schultz RR, Siviero MO, Bertolucci PHF. The cognitive subscale of the "Alzheimer's Disease Assessment Scale" in a Brazilian sample. Braz J Med Biol Res. 2001;34(10):1295-302. doi:10.1590/S0100-879×2001001000009

20. Wechsler D. Wechsler Adult Intelligence Scale. Third Edition (WAIS-III). San Antonio: The Psychological Corporation; 1997.

21. Nascimento E. Adaptação e validação do teste WAIS III para um contexto brasileiro [tese]. Brasília, DF: Universidade de Brasília; 2000.

22. Dourado MCN, Mograbi DC, Santos RL, Sousa MF, Nogueira ML, Belfort T et al. Awareness of disease in dementia: factor structure of the assessment scale of psychosocial impact of the diagnosis of dementia.J Alzheimers Dis. 2014;41(3) 947956. doi:10.3233/JAD-140183

23. Pfeffer RI, Kurosaki TT, Harrah CH, Chance JM, Filos S. Measurement of functional activities in older adults in the community. J Gerontol. 1982;37(3) 323-9. doi:10.1093/geronj/37.3.323

24. Nitrini R, Caramelli P, Bottino CMC, Damasceno BP, Brucki SMD, Anghinah R. [Diagnosis of Alzheimer's disease in Brazil: cognitive and functional evaluation. Recommendations of the Scientifc Department of Cognitive Neurology and Aging of the Brazilian Academy of Neurology]. Arq Neuropsiquiatr. 2005;63(3A):720-7. Portuguese. doi:10.1590/S0004-282X2005000400034

25. Cummings JL, Mega M, Gray K, Rosenberg-Thompson S, Carusi DA, Gornbein J. The Neuropsychiatric Inventory: comprehensive assessment of psychopathology in dementia. Neurology. 1994;44(12):2308-14. doi:10.1212/WNL.44.12.2308

26. Camozzato AL, Kochhann R, Simeoni C, Konrath CA, Franz AP, Carvalho AF et al. Reliability of the Brazilian Portuguese version of the Neuropsychiatric Inventory (NPI) for Alzheimer s disease patients and their caregivers. Int Psychogeriatr, 2008;20(2):383-93. doi:10.1017/S1041610207006254

27. Alexopoulos GS, Abrams RC, Young RC, Shamoian CA. Cornell scale for depression in dementia. Biol Psychiatry. 1988;23(3):271-84. doi:10.1016/0006-3223(88)90038-8

28. Portugal MG, Coutinho ES, Almeida C, Barca ML, Knapskog $A B$, Engedal K et al. Validation of Montgomery-Åsberg Rating Scale and Cornell Scale for Depression in Dementia in Brazilian elderly patients. Int Psychogeriatr. 2012;24(8):1291-8. doi:10.1017/S1041610211002250

29. Gurrera RJ, Moye J, Karel MJ, Azar AR, Armesto JC. Cognitive performance predicts treatment decisional abilities in mild to moderate dementia. Neurology. 2006;66(9):1367-72. doi:10.1212/01.wnl.0000210527.13661.d1

30. Gauthier S, Leuzy A, Racine E, Rosa-Neto P. Diagnosis and management of Alzheimer's disease: past, present and future ethical issues. Prog Neurobiol. 2013;110:102-13. doi:10.1016/j.pneurobio.2013.01.003 